\title{
Arte e gênero androginidade: a dialética do apogeu
}

\author{
'Androgynity' art and gender: the dialetics of apogee
}

\begin{abstract}
Sonia Lyra
Analista Junguiana (IJUSP/AJB/IAAP), Mestre em Filosofia PUCPR e Doutora em Ciências da Religião pela Pontifícia Universidade Católica de São Paulo (PUCSP), Diretora do ICHTHYS Instituto de Psicologia e Religião. Curitiba, PR - Brasil, e-mail: sonia@ichthysinstituto.com.br
\end{abstract}

\section{Resumo}

Método, método, que queres de mim? Bem sabes que comi do fruto do inconsciente, diz Jules Laforgue, em seu Moralités Légendaires. 0 método e a imagem evocam a psicologia do maravilhamento entre o feminino e o masculino na esperança de reanimar o encontro numa nova dialética: andrógina! Não serão abordadas aqui as dimensões físico-biológicas do masculino e do feminino, ainda que não sejam exclusas, mas como diz Henri Bosco em Un rameau de la nuit: as inexauriveis reservas de vida latente que vamos buscar no feminino, sustentado pela força masculina do verbo: anima e animus. A paz dos gêneros, comenta Gaston Bachelard, é procurada pela sabedoria atrativa do esposo e a gravitação amorosa da esposa, a verdadeira situação espiritual, tão terrível e tão bela!

Palavras-chave: Inconsciente. Androginidade. Dialética. Gênero. Sabedoria. 


\section{Abstract}

"Method, method, what do you expect from me? You know very well I have eaten the fruit of the unconscious", said Jules Laforgue in his work 'Moralités Légendaires'. The method and the image evoke the psychology of wonder between the feminine and the masculine looking forward to reviving the encounter in a new dialectics: androgynous! The physical and biological dimensions of the masculine and the feminine, though they are not excluded, will not be dealt with in this study, but, as Henri Bosco says in 'The Dark Bough' (Un rameau de la nuit), "the inexhaustible reserve of latent life" that we search for in the feminine sustained by the masculine strength of the Word and that here will be named as 'anima' and 'animus'. The peace of genders, as Gaston Bachelard commented, is seeked by the attractive wisdom of the husband and the loving gravitation of the wife, the true spiritual situation, so terrible and so beautiful!

Keywords: Unconscious. Androgynity. Dialectics. Gender. Wisdom.

\section{Introdução}

Para Soloview, em Le sens de l'amour, "o homem verdadeiro, na plenitude de sua personalidade ideal, não pode, evidentemente, ser apenas homem ou mulher, mas deve possuir uma unidade superior dos dois sexos" (BACHELARD, 2001, p. 81). Androginia não é apenas uma remota representação de mitos e lendas de união ou da manifestação biológica instintiva, mas se abre na potencialidade do vir a ser que sonha realizar o feminino e o masculino numa determinação para novos valores. A questão talvez seja: feminino/anima e masculino/animus devem ser projetados? Devem ou não ser idealizados? Será a individuação desses princípios anima e animus - a tarefa própria e imediata do amor? É a dialética ${ }^{1}$ que aponta primeiramente para a divisão e subsequentemente para a união desses opostos perpassando seus diferentes significados e em seu apogeu se completa como síntese dos opostos? (ABBAGNANO, 1998)

\footnotetext{
1 Dialética deriva do verbo dialéghesthai, que em grego indica discutir ou raciocinar juntos.
} 
A dialética, como método de discussão, aparece em Platão e consiste em se aproximar do "ponto mais alto que pode chegar a investigação conjunta e compõe-se de dois momentos" (ABBAGNANO, 1998, p. 269): um deles remete para uma ideia única e no modo de defini-la, de tal sorte que possa ser comunicada a todos. Num segundo momento, a dialética é a condição da possibilidade de dividir uma ideia em suas espécies "seguindo suas interações naturais e evitando fragmentar suas partes como faria um trinchador canhestro" (ABBAGNANO, 1998, p. 269). Entre as diferentes abordagens filosóficas da dialética, encontra-se aquela de Platão, que se utiliza do método da divisão para distinguir as espécies de um gênero para depois chegar aos gêneros primeiros. De certa forma, a divisão masculino e feminino conduz a esse gênero primeiro: a androginia. Seguindo a abordagem platônica, os gêneros serão referidos separadamente para, conforme Pedro Ramus, serem vistos como "a própria luz da razão" (ABBAGNANO, 1998, p. 271). Nem todos os filósofos concordam com esse conceito de dialética. Para Hugo de São Vitor, por exemplo, a dialética é a arte das artes e a ciência das ciências porque detém o caminho para chegar aos princípios de todos os métodos. "Só a dialética pode discutir com probabilidade os princípios de todas as outras artes; por isso, no aprendizado das ciências, a dialética deve vir antes" (ABBAGNANO, 1998, p. 272). O conceito também é visto por Santayana como ciência ideal ou formal que compreende a matemática e, com isto, procura esclarecer e desenvolver a essência do que descobrimos. O que nos interessa para este artigo é a dialética considerada como síntese dos opostos, assim como foi pensada por Heráclito e Proclo. Para este último, o procedimento dialético é triádico, ou seja, considera o derivar das coisas do Uno, mas também seu retorno ao Uno. Contemporaneamente, a última "lei" da dialética é a transformação da quantidade em qualidade e vice-versa. Nesse sentido, abordar-se-á primeiramente a divisão do Uno originário em seu par de opostos masculino e feminino, denominados por Jung (1978) como anima e animus.

\section{Anima e animus}

Anima e animus representam as instâncias mais profundas, bem como mais inconscientes da personalidade, que se projetam automaticamente 
sobre os outros e formam as ligações afetivas. Uma relação entre um homem e uma mulher, por exemplo, é sempre uma relação a quatro: além da intenção consciente entre as duas pessoas, abaixo do limiar da consciência encontra-se numa espécie de fogo cruzado, a imagem da anima que o homem carrega e a imagem do animus que a mulher carrega. A escolha do parceiro é feita pela anima e pelo animus de modo inconsciente, isto é, o objeto externo serve de "gancho" para a projeção desses princípios. É a imagem de anima ou animus que possuímos que torna significativo o homem ou a mulher fora de nós. Assim, podem-se encontrar pessoas que por toda a vida se sentem atraídas pelo mesmo modelo de personalidade.

Anima e animus são designados por Jung (1875-1961) em sua Psicologia Analítica como arquétipos, sendo estes um dos componentes mais originais do pensamento junguiano. As origens desse pensamento remontam à filosofia romântica da natureza com a sua doutrina de polaridade das forças cósmicas tocando com isso um antigo mito do andrógino. O eixo dessa doutrina é a concepção da unidade fundante de tudo, especialmente a unidade homem e natureza: uma vida percebida como movimento cósmico, fruto do encontro das polaridades, das forças antagônicas e complementares, cujo símbolo principal está na polaridade masculino-feminino, destacada como cisão da unidade primordial. Especulações sobre as polaridades e sua conotação sexual apontaram para o "risco" de buscar e encontrar o "outro", como possibilidade de ampliação da consciência. A divisão era necessária para que o homem saísse da condição animal ou divina, "onde habitava sem consciência" (CAROTENUTO, 1992, p. 186). A literatura oferece grande número de exemplos, porém uma figura típica da anima é Diotima - aquela que ensina a Sócrates como duvidar de si mesmo. Ao provocar a dúvida, faz surgir também o conhecimento.

Jung observa o tema do primeiro amor no romance de Thomas Hardy The well beloved ${ }^{2}$ (1998). Percebe que, nele, um homem se enamora três vezes ao longo da vida por três mulheres ligadas por laços de sangue e finalmente percebe que sempre esteve enamorado da mesma mulher. Referindo-se ao romance de Rider Haggard She (Ela) e ao Atlantide, de Pierre Benoit, chama de Anima/Gestalt a certo tipo de mulher que parece atrair

\footnotetext{
20 Bem-Amado.
} 
a projeção de anima dos homens. Tristão e Isolda (2006) é outro tipo de romance que aponta para o fenômeno de projeção da anima. Projetar significa transportar de um lugar para outro. Assim o homem transporta a imagem interna que traz da anima, inconscientemente, sobre uma mulher por quem se enamora; ocorre o mesmo com as mulheres que projetam a figura do animus sobre determinado tipo de homem.

Um dos momentos da vida em que se confronta com esse arquétipo é quando o ciclo vital que busca o amor, matrimônio, filhos, etc. é confrontado. Tal confronto traz consigo o conflito, apontando para uma provável animosidade. A animosidade é parte integrante do arquétipo cuja polaridade se constitui em instinto e espírito sendo, por isso, o conflito por excelência do qual fala toda a história da humanidade.

O desenvolvimento do conceito de anima/animus na obra de Jung, por sua natureza contrassexual, acaba por lhe oferecer a possibilidade de formular a conexão entre arquétipo e gene, apontando para o conceito de gênero e sua dependência do número de genes do sexo oposto presentes no indivíduo. A primeira definição ampla que Jung dá de anima e animus encontra-se no volume VI de suas obras completas: Tipos Psicológicos (1921, 1969) (JUNG, 1991).

A questão da anima e do animus é que, quando considerados como modos de ser inconscientes e expressados por certa imagem, são transferidos para determinada pessoa do mundo externo, que se torna objeto de amor intenso ou de sentimentos negativos como o ódio, medo, desconfiança, etc. No volume VII de Estudos sobre Psicologia Analítica (JUNG, 1978), o autor amplia o conceito e o divide em três componentes: a parte de feminilidade do homem e a virilidade da mulher. A experiência que o homem tem da feminilidade e a mulher da masculinidade e a imagem heterossexual hereditária do inconsciente coletivo sem a qual o indivíduo não poderia tomar consciência do outro sexo. Destes três elementos apenas dois podem ser integrados na consciência a partir da experiência com o sexo contrário. Por isso, a mãe e o pai são para a criança os primeiros portadores da imagem da anima e do animus. Mais tarde serão os homens e mulheres que provocam positiva ou negativamente os sentimentos. Esses componentes arquetípicos possuem, pois, características tanto positivas quanto negativas. Ocorre que quanto mais viril a atitude externa de um 
homem, "mais suprimidos são os traços femininos" (JUNG, 1991, p. 392) sendo tais homens portadores de uma fraqueza bem característica: "comportam-se para com as moções do inconsciente com a determinabilidade e impressionabilidade femininas" (JUNG, 1991, p. 392).

Por sua vez, as mulheres mais femininas apresentam quase sempre, em relação a certos componentes internos da psique, "uma ignorância, teimosia e obstinação tão grandes que só poderíamos encontrar na atitude externa do homem" (JUNG, 1991, p. 392). Tais traços tanto no homem quanto na mulher, se excluídos de atitudes externas, podem se tornar qualidades da personalidade, por exemplo, a sensibilidade do homem e a coragem da mulher. Em geral na atitude externa do homem, predomina (ou pelo menos é considerada como convencional) a lógica e a objetividade enquanto que nas mulheres predomina o sentimento. Internamente, porém, a situação se inverte: o homem sente e a mulher delibera. Segundo Jung, é graças a isso que

o homem desespera mais facilmente, ao passo que a mulher ainda consegue consolar e ter esperança; por isso, há mais suicídios entre os homens do que entre as mulheres. Assim como a mulher pode ser muitas vezes vítima das circunstâncias sociais, por exemplo, da prostituição, o homem é vítima dos impulsos do inconsciente, do alcoolismo e outros vícios (JUNG, 1991, p. 392).

Enquanto diferentes etapas do desenvolvimento da personalidade anima e animus podem ser entendidos em quatro etapas propostas por Jung: Anima: O primeiro estágio é simbolizado pela figura de Eva, representando um estágio puramente biológico e instintivo. O segundo estágio pode ser representado pela Helena de Fausto personificando um nível romântico e estético, mas ainda marcado fortemente por elementos sexuais. O terceiro estágio é exemplificado pela Virgem Maria uma vez que esta representa uma figura que eleva o amor à grandeza da devoção espiritual. Finalmente o quarto estágio é representado pela sapiência, uma sabedoria que transcende até mesmo a pureza e a santidade do terceiro estágio, e a figura que a representa pode ser a Sulamita dos Cânticos de Salomão. De modo geral, os aspectos predominantes na contemporaneidade são os do primeiro e segundo estágio sendo usados em 
revistas e filmes com intuito de atração e sedução, além de predominar nos relacionamentos.

Quanto ao animus, também pode ser entendido em quatro etapas de desenvolvimento. No primeiro estágio, aparece como simples personificação da força física e pode ser representado por um atleta ou um ator "sarado", como o Tarzan (Johnny Weismuller). O segundo estágio do animus também é caracterizado por aspectos românticos e pode ser representado por heróis românticos como Schelley, o poeta inglês que tem ao mesmo tempo características de iniciativa e capacidade de planejamento. No terceiro estágio, a figura que representa o animus para a mulher aparece como o "verbo", isto é, professores ou clérigos. Por exemplo, Lloyd George, o grande orador político. Enfim, no quarto estágio, o animus é a "encarnação do pensamento", pode ser representado pelo sábio guia que leva a verdade espiritual, como Gandhi. Esses estágios estão bem desenvolvidos na obra de Jung: O homem e seus simbolos (JUNG, 1977).

Os arquétipos da anima e do animus têm como função principal fazer uma ponte entre a consciência e o inconsciente e aparecem como imagens personificadas nos sonhos e fantasias, além das projeções. A atenção de Jung é dirigida para a ideia de coniunctio do masculino e do feminino, já presentes na filosofia hermética e no gnosticismo, e que ressurgem como símbolos do encontro da consciência masculina com o inconsciente, personificado como feminino.

\section{0 método e a imagem}

Na Psicologia Analítica de Jung, o método é especialmente o da imaginação. É um método especial de introspecção que, na verdade ainda não é propriamente o da imaginação ativa, mas sim "a imaginação que pode tornar-se imaginação ativa quando o diálogo entre a consciência e o inconsciente ocorre" (KAST, 1977, p. 31). A imagem da anima pode surgir inicialmente como um estranho impulso vital, mas traz consigo um significado, isto é, uma sabedoria latente que contrasta com a sua natureza irracional. $\mathrm{O}$ aspecto de sabedoria, último estágio de desenvolvimento da anima sob esse aspecto somente aparecerá para aquele que com ela 
se confrontou seriamente ao longo da vida. Nos primeiros estágios de desenvolvimento, a imagem do animus é projetada e idealizada sobre os homens, por exemplo, como já mencionado o "príncipe encantado"; ou estranhamente em idealizações de projetos e atividades destinados ao fracasso. Naturalmente, também a anima pode aparecer como um demônio de destruição e de morte.

O método visa a transformar a imagem em função de relação. Com isso, a técnica de diferenciação entre o eu e as figuras do inconsciente é fundamental, ou seja, é preciso despotencializar a sedução produzida pelas imagens personificadas de anima e animus contrapondo-se conscientemente a elas. Contrapor aqui é mais um confrontar que um eliminar. As figuras, como seus modos de ser, não podem ser eliminados ou excluídos, mas sim, quando possível, integradas. Quando não integrados esses arquétipos, dão lugar às possessões porque tanto a anima quanto o animus em estado inconsciente, são decididamente privados de relações, autoeróticos, e levam o indivíduo a ser continuamente "tomados" por eles. Paralisam o eu (ego) e atuam autonomamente levando o indivíduo a fazer ou dizer o que não quer, gerando um estado unilateral da consciência. Aqui, a psicoterapia torna-se fundamentalmente um confronto do eu com a imagem da anima/animus constituindo um conflito e um problema de difícil solução uma vez que aparece desse modo nas relações dos pares de opostos masculino e feminino.

\section{Conclusão}

Quando se pensa nesse par de opostos anima/animus, é comum emergir a questão referente à homossexualidade e à bissexualidade, ou, ainda, à transsexualidade. Não é o propósito deste artigo abordar questões de gênero dessa monta, mas pode-se dizer que os arquétipos anima e animus independem completamente da orientação sexual de homens e mulheres, ainda que, na homossexualidade feminina, possam estar acentuados os traços masculinos da personalidade e na homossexualidade masculina acentuados os traços femininos da personalidade. $O$ fator para o qual essa dialética aponta não é relativo a esses comportamentos 
externos, mas, sim, ao modo como se projetam no sexo oposto, que é sempre idêntico, tanto em heterossexuais quanto em homossexuais, por serem elementos constituintes de uma dinâmica interna, que visa ao desenvolvimento do Homem Interior.

Se a imagem da anima não foi ainda diferenciada e posteriormente integrada, é provável que as suas relações afetivas sejam animosas até o ponto da mais grave patologia. Um psicótico interno no Manicômio Judiciário, há muitos anos, pensando salvá-la da dor e sofrimento deste mundo, degolou-a. Se a imagem da anima não estivesse projetada, a figura que ele salvaria das dores do mundo seria interna sua e integrado a ela a psicose daria lugar a uma ampliação da consciência. Também não é nosso propósito definir, aqui, os diferentes momentos do conceito de consciência ou de inconsciente.

O que se pode frisar como fundamental desta abordagem é a possibilidade da androginidade, isto é, a retirada da projeção das pessoas do mundo externo, o que é extremamente difícil de se conseguir conscientemente. Naturalmente, com o transcorrer do tempo, aquele fascínio provocado pela atração de anima e animus num relacionamento afetivo, positivo ou negativo, pode ir sendo despotencializado e chega-se à conclusão, muitas vezes frustrantes, de que o outro era "apenas um ser humano" com uma grande gama de limitações e/ou patologias constituintes da sua estória. No entanto, se a projeção puder ser retirada, tornando consciente o conteúdo afetivo que fez a ligação, isso reverte para uma ligação do sujeito consigo mesmo. Quando projetados, anima e animus geram a divisão interna do indivíduo. Em virtude disso, é que se busca a "outra metade" ou a "alma gêmea" ou enfim, o complemento que falta. Quando elaborados num nível interno, vão gradativamente preenchendo a "falta" e conduzindo a dimensões mais profundas da psique. Como foi mencionado nos estágios de desenvolvimento, a instintividade "animal" do primeiro estágio vai sofrendo transformações e apontando para a possibilidade de se atingir o último degrau do desenvolvimento, que é a sabedoria.

Filósofos de todos os tempos buscam definir, a partir de muitos pontos de vista, a sabedoria. Neste caso, aqui proposto, a sabedoria aparece como o resultado da união desses opostos no interior do homem, na 
androginia do Homem Interior. $\mathrm{O}$ homem adquire a sensibilidade e a capacidade de amar próprios do feminino, enquanto que a mulher adquire a objetividade e a coragem de se posicionar na vida próprios do masculino. Não deste ou daquele homem ou mulher, mas diante da assimilação das características mais positivas desses arquétipos, transformando a instintividade inconsciente em espiritualidade. Se o indivíduo não se propõe, conscientemente, a essa integração de anima e animus, sofrem tanto a cultura como a civilização.

\section{Referências}

ABBAGNANO, N. Dicionário de filosofia. São Paulo: M. Fontes, 1998.

BACHELARD, G. A poética do devaneio. São Paulo: M. Fontes, 2001.

BENOIT, P. L'Atlantide. Paris: Albin Michel, 1927.

BOSCO, H. Un rameau de la nuit. Paris: Flammarion, 1950.

CAROTENUTO, A. Trattato di psicologia analítica: la dimensione clinica. Torino: UTET, 1992.

FURY, D. Johnny Weissmuller: twice the hero. Minneapolis: Artist's Press, 2000.

HAGGARD, R. She. New York: Barnes and Noble Books, 2004.

HARDY, T. The well-beloved: a sketch of a temperament. New York: Harper \& Brothers, 1912.

JUNG, C. G. 0 homem e seus símbolos. São Paulo: M. Fontes, 1977.

JUNG, C. G. Estudos sobre psicologia analítica. Petrópolis: Vozes, 1978.

JUNG, C. G. Tipos psicológicos. Petrópolis: Vozes, 1991.

KAST, V. A imaginação como espaço de liberdade: diálogo entre o ego e o inconsciente. São Paulo: Loyola, 1997. 
KENNETH, O. M. Lloyd George (British prime ministers). England: Littlehampton Book Services, 1974.

LAFORGUE, J. Moralités legendaires. Paris: Flammarion, 2009.

SHAKESPEARE, W. Tristão e Isolda. England: Kindle, 2006.

Recebido: 26/06/2011

Received: 06/26/2011

Aprovado: 23/10/2011

Approved: 10/23/2011 